NATIONAL LABORATORY

\title{
Benefits of Daily File Analysis Using DART
}

May 2013

Prepared by

Angela Lousteau

Georgia Adams

Alexander Enders

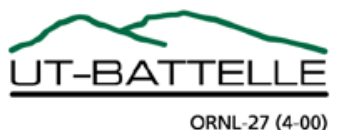




\section{DOCUMENT AVAILABILITY}

Reports produced after January 1, 1996, are generally available free via the U.S. Department of Energy (DOE) Information Bridge.

Web site http://www.osti.gov/bridge

Reports produced before January 1, 1996, may be purchased by members of the public from the following source.

National Technical Information Service

5285 Port Royal Road

Springfield, VA 22161

Telephone 703-605-6000 (1-800-553-6847)

TDD 703-487-4639

Fax 703-605-6900

E-mail info@ntis.gov

Web site http://www.ntis.gov/support/ordernowabout.htm

Reports are available to DOE employees, DOE contractors, Energy Technology Data Exchange (ETDE) representatives, and International Nuclear Information System (INIS) representatives from the following source.

Office of Scientific and Technical Information

P.O. Box 62

Oak Ridge, TN 37831

Telephone 865-576-8401

Fax 865-576-5728

E-mail reports@osti.gov

Web site http://www.osti.gov/contact.html

This report was prepared as an account of work sponsored by an agency of the United States Government. Neither the United States Government nor any agency thereof, nor any of their employees, makes any warranty, express or implied, or assumes any legal liability or responsibility for the accuracy, completeness, or usefulness of any information, apparatus, product, or process disclosed, or represents that its use would not infringe privately owned rights. Reference herein to any specific commercial product, process, or service by trade name, trademark, manufacturer, or otherwise, does not necessarily constitute or imply its endorsement, recommendation, or favoring by the United States Government or any agency thereof. The views and opinions of authors expressed herein do not necessarily state or reflect those of the United States Government or any agency thereof. 


\title{
BENEFITS OF DAILY FILE ANALYSIS USING DART
}

\author{
Angela Lousteau \\ Georgia Adams \\ Alexander Enders
}

Date Published: May 2013

\author{
Prepared by \\ OAK RIDGE NATIONAL LABORATORY \\ Oak Ridge, Tennessee 37831-6283 \\ managed by \\ UT-BATTELLE, LLC \\ for the \\ U.S. DEPARTMENT OF ENERGY \\ under contract DE-AC05-00OR22725
}





\section{CONTENTS}

\section{Page}

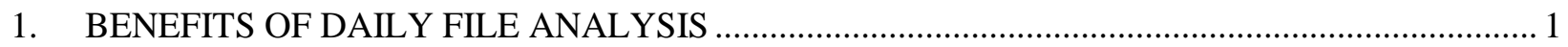

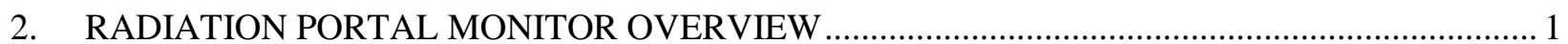

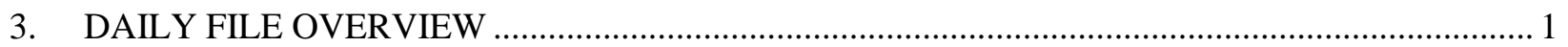

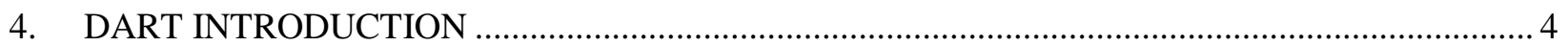

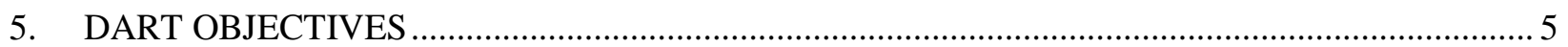

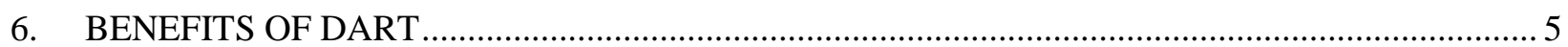

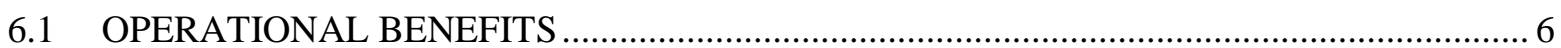

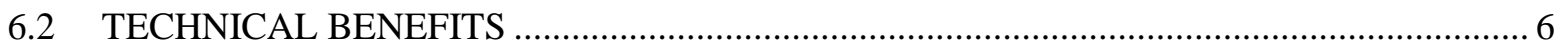

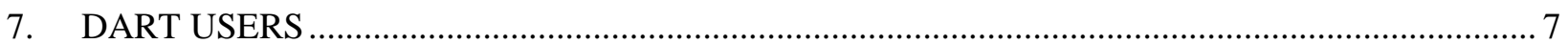

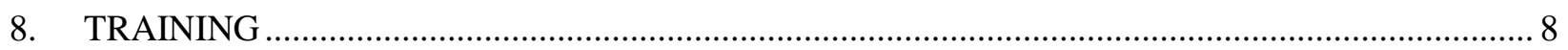

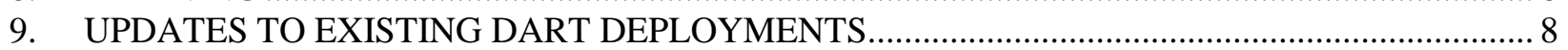

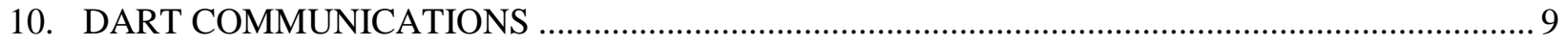

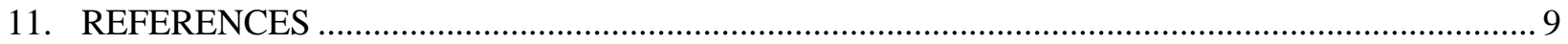





\section{BENEFITS OF DAILY FILE ANALYSIS}

Data analysis is an integral part of the Second Line of Defense (SLD) program to ensure that radiation monitoring equipment is operating effectively. Oak Ridge National Laboratory (ORNL) has developed the Desktop Analysis Reporting Tool (DART), which allows SLD users to easily analyze daily file data and to determine the state of health of the monitors. Currently, SLD analysts at ORNL use the DART software to review radiation portal monitor (RPM) data and to generate reports that provide findings to SLD country, project, and sustainability managers.

As more sites reach the transition phase, the SLD program wants to expand the benefits of its data analysis capability to SLD partner countries. As with any SLD capability offered to partner countries, SLD country managers and project teams can help SLD partner countries understand the benefits of data analysis and then work together to determine how to best use DART.

\section{RADIATION PORTAL MONITOR OVERVIEW}

The SLD program works with partner countries to enhance their ability to deter, detect, and interdict the illicit trafficking of nuclear and radiological materials through border crossings, airports, and ports around the world by providing RPMs and other radiation detection devices. RPMs, the workhorse of this effort, consist of various arrays of scintillating gamma detectors and ${ }^{3} \mathrm{He}$-based neutron detectors. The RPMs constantly monitor radiation levels to detect elevation above a given threshold, at which time the monitors alarm or send alarms to a central alarm station (CAS).

The data collected by the RPMs are written into daily files stored at the CAS. Daily files are transferred to ORNL for data analysis through an ORNL File Transfer Protocol (FTP) site. Once uploaded, ORNL downloads the files and deletes them from the FTP site.

\section{DAILY FILE OVERVIEW}

A daily file is nothing more than a compact (ASCII) text-encoded file that contains RPM-specific information for a 24-h time period; it contains no information related to the cargo, container numbers, videos or photos, or manifest or alarm resolution information. As indicated by their name, daily files for each RPM are generated daily by the CAS. The contents of the daily files are written by the RPMs. The SLD program uses the data in the daily files to ensure that the installed systems are operating correctly and to optimize detection capability and sensitivity of the RPMs.

Daily files contain information related to the RPM settings (e.g., alarm thresholds, occupancy hold-ins, discriminator settings, firmware version), the count rates observed by the monitor for each gamma and neutron detector, information related to fault conditions experienced by the RPMs, and alarm values for all detectors contained in the RPMs. Each line in the daily files is time-stamped. Additional information can be determined by processing the data.

The SLD program uses the daily files for several purposes:

- To determine whether the RPM portal is operating properly. Although fault alarms indicating detector failures (e.g., high gamma) are recorded in the event file, the individual channel count rates stored in the daily file allow the SLD user to better identify and diagnose detector failures; 
- To perform trend analysis on the operation of the RPM. For example, the number of alarms per day and number of vehicles scanned per day can be used to approximate the staffing needs of the site;

- To track alarm thresholds and other important RPM parameter settings that affect the detection capability of the system installed; and

- To optimize RPM performance by determining the needed sensitivity to detect materials of concern while minimizing the number of innocent alarms.

To perform useful data analysis on RPMs, it is important to fully understand the information available in the daily file. The daily file excerpt in Fig. 1 shows a subset of the data strings available in the daily files with a short description of the string. Keep in mind that one average-sized daily file contains $\sim 40,000$ lines of data. 


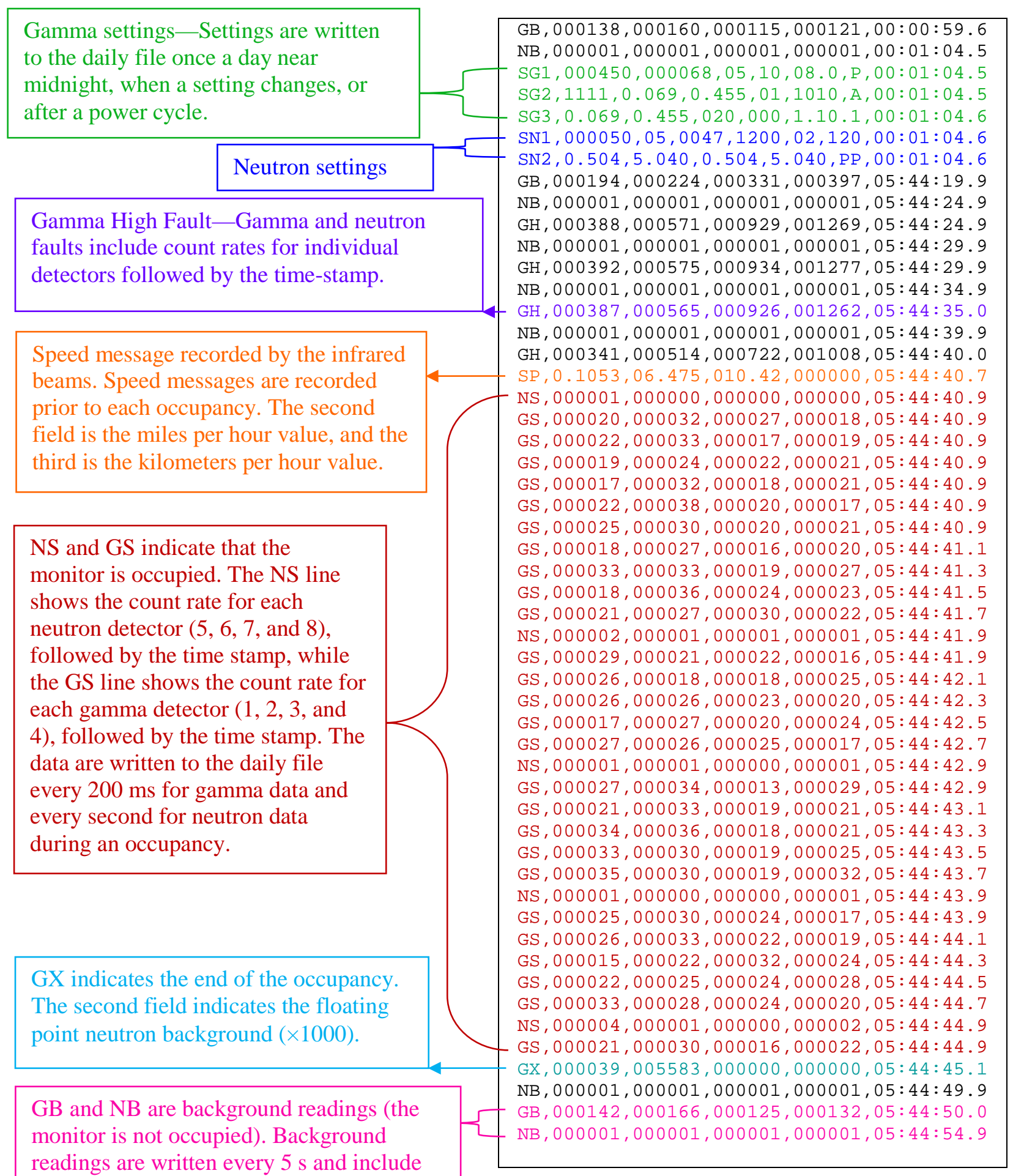
the count rates from each detector, followed by the time stamp.

Fig. 1. Daily file excerpt. The irregularity of the time stamp in the excerpt may be disregarded. 


\section{DART INTRODUCTION}

ORNL developed DART to effectively use data in the daily files. DART aids its users in filtering through large amounts of daily file data to determine how to best manage, maintain, and maximize detection efficiency of the RPMs. Additionally, DART can help the user identify operational and maintenance related issues. Essentially, DART extracts information from the daily files (see Fig. 2) and stores it in a Structured Query Language (SQL) or SQL Express database that can be manipulated to yield tables, graphs, and charts (see Fig. 3).

GB, $000124,000128,000141,000123,13: 28: 58.3$ $\mathrm{NB}, 000001,000001,000001,000001,13: 29: 03.2$ $\mathrm{GB}, 000122,000128,000143,000123,13: 29: 03.3$ $\mathrm{NB}, 000001,000001,000001,000001,13: 29: 08.2$ GB, $000124,000126,000145,000124,13: 29: 08.3$ $N B, 000001,000001,000001,0000 \odot 1,13: 29: 13.2$ $\mathrm{GB}, 000127,000126,000142,000128,13: 29: 13.3$ NS, $0000 \odot 2,000002,00000 \odot, 000005,13: 29: 16.8$ GS, $\odot \odot \odot \odot 20,0 \odot \odot \odot 26,0 \odot \odot \odot 28,0 \odot \odot \odot 22,13: 29: 16.9$ GS, $000035,000 \odot 27,000031,000031,13: 29: 16.9$ GS, $000027,000019,000023,000020,13: 29: 16.9$ GS, $000023,000 \odot 30,00 \odot \odot 21,00 \odot \odot 23,13: 29: 16.9$ GS, $000014,000030,000023,000030,13: 29: 16.9$ GS, $000021,000019,000 \odot 24,000022,13: 29: 16.9$ SP, $0.0915,07.452,011.99,000000,13: 29: 17.0$ GS, $\odot \odot \odot \odot 32,0 \odot \odot \odot 17,0 \odot \odot \odot 28,0 \odot \odot \odot 21,13: 29: 17$. $\odot$ GS, $000014,000019,000028,000029,13: 29: 17.2$ $\mathrm{SP}, 0.0871,07.828,012.60,000000,13: 29: 17.2$ GS, $0 \odot \odot \odot 21,0 \odot \odot \odot 23,0 \odot \odot \odot 26,0 \odot \odot \odot 28,13: 29: 17.4$ GS, $000027,000 \odot 24,000034,000022,13: 29: 17.6$ NS, $000001,000002,000001,000001,13: 29: 17.8$ GS, $00 \odot \odot 25,0 \odot \odot \odot 22,0 \odot \odot \odot 26,0 \odot \odot \odot 21,13: 29: 17.9$ GS, $000020,000019,000029,000029,13: 29: 18 . \odot$ GS, $000023,000020,000029,000023,13: 29: 18.2$ GS, $000023,000027,000030,000030,13: 29: 18.4$ GS, $000023,000018,000021,000025,13: 29: 18.6$

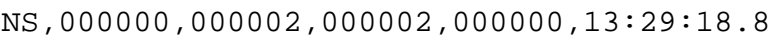
GS, $000030,000 \odot 25,000024,000021,13: 29: 18.9$ GS, $\odot \odot \odot \odot 24,0 \odot \odot \odot 26,0 \odot \odot \odot 25, \odot \odot \odot \odot 3 \odot, 13: 29: 19 . \odot$ GS, $0 \odot \odot \odot 31,0 \odot \odot \odot 21,0 \odot \odot \odot 33,0 \odot \odot \odot 31,13: 29: 19.2$ GS, $000028,000033,000022,000027,13: 29: 19.4$ GS, $000032,000022,000025,000031,13: 29: 19.6$ NS, $000002,000002,000000,000001,13: 29: 19.8$ GX, $000001,005191,000000,000000,13: 29: 19.9$ NB, $0 \odot \odot \odot \odot 1,0 \odot \odot \odot \odot 1,00 \odot \odot \odot 1,0 \odot \odot \odot \odot 1,13: 29: 24.6$ $\mathrm{GB}, 000129,000123,000137,000126,13: 29: 24.7$ NB, $000001,000001,000001,000001,13: 29: 29.6$

Fig. 2. Strings of data from a daily file. 


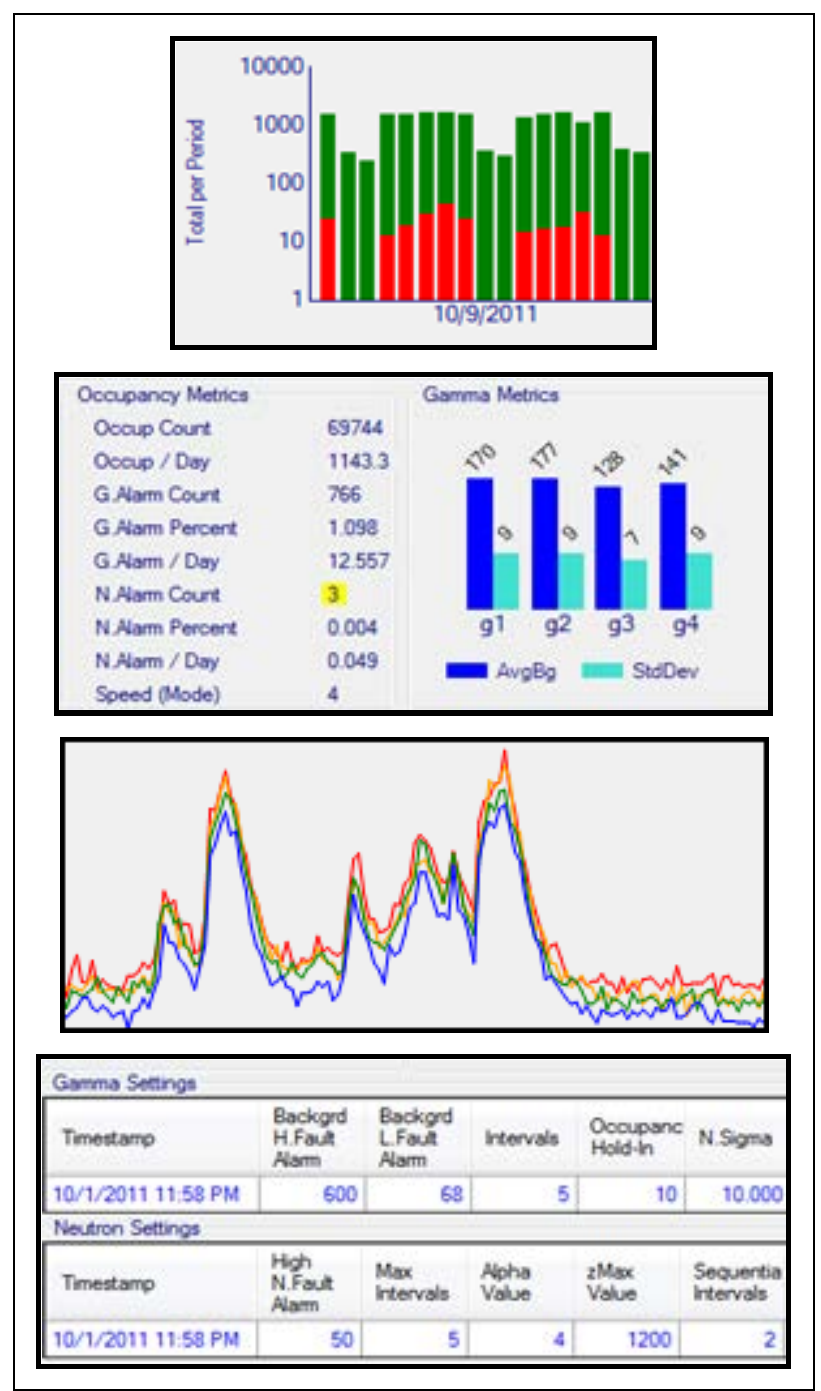

Fig. 3. Graphs and tables generated in DART.

\section{DART OBJECTIVES}

The goal of distributing DART to SLD partner countries is to institute an in-country data analysis capability. To meet this goal, it is important to communicate to SLD stakeholders the tremendous importance of data analysis and the role DART can play in easing the burden of data analysis for partner countries.

\section{BENEFITS OF DART}

The SLD program uses DART as a program management tool to ensure the radiation portals are being used as intended and systems are maintained in a configuration consistent with SLD guidelines. SLD partners are able to realize these same advantages; additionally, SLD partners can implement DART for their respective site(s) in ways that best benefit their site operations. DART also enables SLD partners to 
collect and obtain a deeper understanding of the systems and system behaviors by targeting specific RPMs and their associated hardware.

\subsection{OPERATIONAL BENEFITS}

The use of DART by a trained analyst will provide a site with both technical and operational benefits. Examples of operational benefits are listed below:

- Staffing requirements—determine staffing requirements for a site based on number of occupancies per hour, day, and month;

- Alarm rates - determine percentage of occupancies that generate gamma and/or neutron alarms and whether percentage is manageable for a site;

- Naturally occurring radioactive material (NORM) distribution across all cargo-determine collective distribution of radioactivity for all cargo containers passing through the RPMs (this is key to mitigating the effects of high NORM alarm rates, for instance);

- Traffic control—evaluate speed of vehicles passing through monitors and identify traffic flow, crowding, and tailgating issues;

- System access - use tamper indicators to verify authorized or unauthorized access to equipment (e.g., by maintenance or other site personnel);

- Operations oversight—-track the duration of time a portal is operational;

- Maintenance management — confirm that repairs were completed and that the issue was resolved; and

- Configuration management-monitor and track RPM settings and parameters, which determine the efficacy of site system performance

\subsection{TECHNICAL BENEFITS}

DART provides SLD users with insights into the system for a more in-depth understanding of system operations, leading to better performance and improved sustainability of detection systems:

- Reachback - review data to determine date and time of alarm, profile shape, and occupancy duration, and use the alarm profile to differentiate between sources;

- System health—determine whether RPMs are working properly, and if not, diagnose problems;

- System trends - track the data from RPMs to determine whether the data are reliable and consistent and to determine whether there are issues such as crowding, speed control, or environmental factors impacting RPM performance;

- Detectors - determine whether specific detectors within each RPM are on line and operating normally;

- Communications - determine whether communication between RPM and CAS is operating normally;

- Interference-identify nearby sources or activity that may interfere with equipment; 
- Diagnostics - pinpoint the date and times of issues identified in the data to help minimize downtime and diagnose and/or narrow the location of a problem.

- Intermittent failure diagnosis—identify and report intermittent component failures; such failures can be difficult for maintenance technicians (who may be present for only a few minutes) to diagnose and repair; and

- Predictive maintenance-identify failing components (radiation detectors, high-voltage power supplies) for replacement before they become an operational burden.

\section{DART USERS}

DART provides both operational and technical benefits to SLD sites to help partners more effectively and efficiently operate and sustain the installed SLD systems. Possible users of DART include:

- Owners of the radiation detection systems (the agency or party responsible for managing and ultimately receiving the equipment from SLD, which may or may not be the RPM operating entity) interested in the operational effectiveness of the RPMs;

- Local maintenance providers interested in and capable of maintaining the RPM hardware; and

- Competent authorities (or agencies responsible for responding to radiological or nuclear events in country) interested in reachback information related to alarms and alarm profiles .

Regardless of the user, it is important to provide DART training to SLD partners to ensure the effective assimilation of data analysis capabilities. There are several factors to consider such as data storage capacity before installing DART in an SLD country:

- A computer must be available to perform data analysis;

- Access and ability to transfer daily files must be available to the machine performing analysis;

- Use of DART (specifically the processing of daily files) risks slowing down the speed of other system processes;

- $\quad$ The computer must be configured with .NET 3.5 and run with Windows XP, Windows Vista, or Windows 7;

- The DART executable and supplementary program files require less than $5 \mathrm{MB}$; however, the database storing extracted data can be as large as $10 \mathrm{~GB}$; and

- $\quad$ The speed of the search, metric retrieval, charting functions, and PDF generation, which are memoryintensive, will be greatly influenced by the amount of available RAM and number of processors on a system. 


\section{TRAINING}

ORNL has developed a 6 to $8 \mathrm{~h}$ Introduction to DART curriculum to provide partner country stakeholders with the basic skills to use DART effectively at SLD sites. The course includes presentation material, a walk-through of the software, and an extensive hands-on exercise where students analyze multiple systems and identify problems. ORNL subject matter experts (SMEs) or approved maintenance training team (MTT) trainers can provide instruction on its application, installation, analysis, and reporting capabilities.

After completing DART training, users should be able to meet the following objectives:

- Installing and using DART

- Successfully install SQL Express and configure DART to integrate with SQL Express;

- Set up a representative location hierarchy for a country, site, and lane (including the importance of the Upload File Pattern); and

- Show proficiency in the process of importing data (file placement, extracting data, and handling errors).

- Performing data analysis

- Understand the expected or standard values for data metrics (data availability, occupancy metrics, and background metrics);

- Recognize the importance of highlighted fields, including settings and changes;

- $\quad$ Recognize the signs of a failing gamma or neutron detector;

- $\quad$ Understand the expected or standard values for settings (both gamma and neutron);

- Review alarms as a diagnostic tool to examine detector health;

- Show proficiency with data histograms as a way to evaluate site operations and system health; and

- Generate a monthly report.

\section{UPDATES TO EXISTING DART DEPLOYMENTS}

Updates and improvements are made periodically to the DART software. These updates may include new or improved analysis capabilities; better, more streamlined reporting functions; improved user interfaces; new language support; or corrections for identified problems. Some updates include structural changes to the DART database, while others include changes only to the interface. Regardless of the changes made to new versions of DART, updates to existing DART deployments may be completed remotely.

To minimize resources associated with updating existing deployments of DART, the ORNL FTP site may be used to send updated versions to SLD partners. Step-by-step instructions to update existing versions of DART are available. It is important to note the following: 
- $\quad$ Updating existing versions of DART does not require changes to SQL Express;

- Updating DART typically takes 5 to 10 minutes;

- Populated databases (containing already processed daily files) may or may not be overwritten, depending on the current version of DART being used; and

- Training on updates and new capabilities may be completed remotely via WebEX.

\section{DART COMMUNICATIONS}

Please contact Angie Lousteau (lousteaula@ornl.gov) for more information on obtaining DART or DART training.

\section{REFERENCES}

1. Lousteau, A. and Alcala, S.; "Desktop Analysis Reporting Tool (DART) User's Guide”; Oak Ridge National Laboratory report ORNL/TM-2013/218; 2013. 